\title{
REDAÇÕES, CARTAS E COMPOSIÇÕES LIVRES: O CADERNO ESCOLAR COMO OBJETO DA CULTURA MATERIAL DA ESCOLA (LAGES/SC - 1935)
}

DOI: http://dx.doi.org/10.1590/2236-3459/58637

\author{
Tania Cordova \\ Universidade do Estado de Santa Catarina, Brasil.
}

$\cos 8$

\begin{abstract}
Resumo
O caderno escolar é um objeto da cultura material que possibilita à História da Educação compreender o cotidiano da escola. Esse trabalho investigou as práticas de escrita em um caderno de produção de textos pertencente a uma ex-aluna da Escola Normal de Lages, interior do Estado de Santa Catarina, no ano de 1935. Nessa investigação o caderno representou um documento que permitiu entrever parte do processo de negociação entre o prescrito pelo currículo, o trabalho pedagógico e os tipos de escritas desenvolvidas pela normalista. Foram analisadas escritas presentes em redações, cartas e composições livres. O uso do caderno como documento possibilitou compreender as apropriações e os usos deste objeto como portador de sentidos ligados ao sistema de valores e representações sociais que ultrapassam a função de objeto destinado, somente, ao registro do processo de aprendizagem.

Palavras-chave: cadernos escolares, história da educação, cultura material, práticas de escrita.
\end{abstract}

\section{ESSAYS, LETTERS AND FREE COMPOSITIONS: THE NOTEBOOK AS OBJECT OF SCHOOL MATERIAL CULTURE (LAGES/SC - 1935)}

\begin{abstract}
The school notebook is an object of material culture that enables history of education to understanding the school's daily life. This work investigated the writing practices in a text production notebook belonging to a former student of the Normal School of Lages, State of Santa Catarina, in the year of 1935. In this research, the school notebook represented a tool that has allowed to see part of the negotiation process between the prescribed by the curriculum, the pedagogical work and the types of writing styles developed by the normalist. Writings were analyzed in texts, such as: essays, letters and free compositions. The use of the notebook as document/source made it possible to understand the appropriations and the uses of this object as bearer of meanings attached to a system of values and social representations that goes beyond the object function aimed only at the record of the learning process.

Key-words: school notebooks, history of education, material culture, writing practices.
\end{abstract}




\title{
ENSAYOS, CARTAS Y COMPOSICIONES LIBRES: LO CUADERNO ESCOLAR COMO EL OBJETO DE LA CULTURA MATERIAL DE LA ESCUELA (LAGES/SC - 1935)
}

\begin{abstract}
Resumen
El cuaderno escolar es un objeto de la cultura material que permite a la Historia de la Educación a entender lo cotidiano de la escuela. Este estudio investigó las prácticas de escritura en un cuaderno de producción de textos pertenecientes a una ex-alumna de la Escuela Normal de Lages, interior del Estado de Santa Catarina, en el año de 1935. En esta investigación, el cuaderno representa una herramienta que permite a vislumbrar parte del proceso de negociación entre prescrito por el currículo, el trabajo pedagógico y los tipos de escritura desarrollado por normalista. Se analizaron las escritas presentes en textos tales como ensayos, cartas y composiciones libres. El uso del cuaderno como un documento/ fuente ha permitido entender la apropiación y los usos de este objeto como portador de significado conectado con el sistema de valores y representaciones sociales que van más allá de la función objeto destinado sólo para el registro del proceso de aprendizaje.

Palabras-clave: cuadernos escolares, historia de la educación, cultura material, práctica de escritura.
\end{abstract}

\section{RECITS, LETTRES ET ESSAIS: LE CAHIER D'ECOLIERE COMME OBJET DE LA CULTURE MATERIELLE DE L'ECOLE (LAGES/SC - 1935)}

Résumé

Le cahier d'école est un objet de la culture matérielle qui rend possible à l'Histoire de l'éducation comprendre le quotidien de l'école. Ce travail s'est intéressé pour les pratiques d'écriture dans un cahier de production de textes, appartenant a une ex-étudiante de L'Ecole Normale de Lages, dans l'État de Santa Catarina, dans l'année de 1935. Dans cette recherche, le cahier a représenté un outil qui permet pour identifier une partie du processus de négociation entre ce qui était prescrit dans le curriculum, le travail pédagogique et les écrits développés par l'étudiante. Des écrits présentés sous la forme de récits, lettres et essais ont été analysés. L'usage du cahier comme source d'information a rendu possible comprendre les appropriations et les usages de cet objet, comme porteur de sens liés au système de valeur et les représentations sociales qui vont au delà de la fonction objet destiné uniquement à l'enregistrement du processus d'apprentissage.

Mots-clé: cahier d'école, histoire de l'éducation, culture matérielle, pratique d'écriture. 


\section{Introdução}

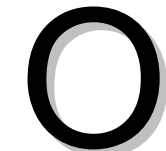

interesse pela vida cotidiana e pela cultura escolar lança novos olhares aos objetos da escola. O caderno escolar é um dos objetos que permite ao pesquisador compreender a instituição de ensino e o seu cotidiano. Como produto da cultura escolar, o caderno configura uma frente de possibilidades de investigação que pode ser dimensionada em diferentes áreas da pesquisa histórica. Sobre essa proposição Viñao Frago (2008) sinaliza que os cadernos escolares "são fontes não menos complexas que outras, as quais, nas últimas décadas, figuram no cruzamento de três campos historiográficos relacionados e complementares: a História da Infância, a História da Cultura Escrita e a História da Educação" (p. 15).

Ao considerar os cadernos escolares como documentos é necessário perspectiválos a partir de algumas possibilidades de análise. De acordo com Mahamud Angulo (2012), a primeira reside na constituição destes objetos como suporte das escritas escolares, denominadas de cotidianas ou ordinárias ${ }^{1}$. A segunda diz respeito aos cadernos serem vestígios da transposição real do currículo oficial para a prática educativa ou, também, de desvio dos cumprimentos do currículo prescrito. Uma terceira possibilidade está associada ao fato de tais objetos permitirem problematizar os aspectos socioeducativos da ação pedagógica do professor, em que é possível perceber a marca pessoal da prática docente, a transmissão de modelos, valores e atitudes, sentimentos e a formação de hábitos de trabalho. Por último, os cadernos escolares são lugares em que se permite compreender a construção do aluno, as opções, as escolhas, as apropriações, as ressignificações. Enfim, os cadernos possibilitam esquadrinhar "o cotidiano escolar a partir da ótica do aluno e do professor, em suas manifestações táticas de organização, mobilização e produção das ações de uso de tais objetos didáticos" (Kirchner, 2013, p. 2).

Dentro desta perspectiva pretende-se problematizar as práticas de escrita presentes em um caderno de produção de textos pertencente à Isolina Gamborgi, filha de um destacado proprietário de terras na região da serra catarinense e aluna da primeira turma da Escola Normal Secundária, localizada na cidade de Lages, interior do Estado de Santa Catarina, na década de 1930. O objetivo em utilizar o caderno desta aluna como fonte histórica se inscreve na esteira da investigação clássica de Gvirtz (1997), que registrou a utilização de cadernos escolares como fontes que oportunizam uma forma de aproximação para os estudos sobre as práticas da escola. $O$ desenrolar dessas práticas representa um processo de negociação do currículo prescrito e as formas como este currículo é dado a circular na escola.

Neste trabalho o caderno da ex-normalista representa um documento que possibilitou a pesquisa entrever parte do processo de negociações entre o prescrito pelo currículo, o trabalho pedagógico executado pelo professor e os tipos de textos desenvolvidos pela normalista. Para tal identificaram-se práticas escriturárias presentes em produções textuais tais como redações, cartas e composições livres. As marcas de

\footnotetext{
${ }^{1}$ Segundo Ana Chrystina Venâncio Mignot e Maria Teresa Santos Cunha (2006), as escritas cotidianas e ordinárias são as escritas produzidas pelo sujeito comum. As escritas presentes nos cadernos escolares são consideradas ordinárias e passaram a ser percebidas como documentos para a historiografia a partir da década de 80 do século 20, quando a abordagem da História Cultural rompeu com o modelos positivistas e inseriu no rol da investigação tudo aquilo que é produzido, fabricado pelo homem comum. Desta forma, os objetos da escola, entre eles os cadernos escolares, são considerados como produtos da cultura escolar e, como tal, documentos sobre os quais se podem construir a História.
} 
correção, realizadas pelo professor, também, foram analisadas neste trabalho e possibilitaram, mesmo que indiciariamente, compreender as apropriações e os usos deste objeto como portador de sentidos ligados ao sistema de valores e representações sociais que ultrapassam a função de objeto destinado, somente, ao registro do processo de aprendizagem.

Badanelli Rubio e Mahamud Ângulo (2008) alertam que o caderno escolar pode testemunhar o que se pretende ensinar aos alunos, porém, nem sempre é capaz de mostrar tudo o que foi aprendido em dado momento escolar. Esta proposição alerta para o entrecruzamento de documentos, isto é, o caderno escolar também pode ser complementado com livros didáticos, manuais, trabalhos de alunos, atas de inspeção, propostas pedagógicas, autobiografias, informações obtidas por meio de relatos orais, entre outras. Neste trabalho, o Regimento das Escolas Normais de Santa Catarina e o Programa de Ensino constituíram importantes documentos para tensionar o prescrito e o realizado nas práticas escriturárias.

O texto organiza-se em três tópicos que mobilizam o caderno como documento nas investigações que ajudam a compreender a complexa construção da cultura da escola. No primeiro tópico apresenta-se o caderno como objeto da cultura material da escola; no segundo percorre-se o cenário da emergência das escolas normais em Santa Catarina, bem como a composição do currículo aplicado nestas instituições de ensino e, no terceiro, apontam-se as marcas de escrita presentes no caderno da ex-aluna da Escola Normal em Lages.

\section{O caderno como objeto da cultura escolar}

As escritas cotidianas ou ordinárias ganharam visibilidade no campo da investigação da História da Cultura Escrita e da História da Educação (Viñao Frago, 2008). Estas escritas têm sido dimensionadas pela pesquisa historiográfica, não somente como parte do consumo passivo dos conteúdos escolares, mas como práticas cotidianas de consumidores que desenvolvem táticas para fugir de uma prescrição, de uma norma estabelecida e desenvolver gostos, práticas e as próprias artes de fazer (Certeau, 1994). Ou seja, para além do consumo puro e simples, os praticantes da vida cotidiana da escola - professores e alunos - desenvolvem ações, fabricam formas alternativas de uso de regras e produtos com os quais convivem, tornando-se produtores ou autores e disseminam outras possibilidades para manipulá-las ao seu modo, mesmo que de forma quase invisível e marginal (Certeau, 1994).

Assim, as escritas cotidianas e ordinárias encontradas nos cadernos escolares são indícios que contribuem para a compreensão da pluralidade de redes tecidas entre alunos e escola, marcadas pela singularidade de cada um no uso desse objeto, o que permite refletir acerca dos possíveis usos e significados.

Ao tratar das escritas cotidianas e ordinárias, na perspectiva da cultura escolar, Maria Teresa Santos Cunha (2007) destaca que os materiais produzidos por alunos são vestígios que guardam memórias da educação escolarizada e possibilitam rastrear o conjunto de códigos culturais nele escritos. Além disso, permitem ao pesquisador o reconhecimento de um sistema de regras culturalmente construídas e encarnadas nas concepções da pedagogia. 
O uso das escritas ordinárias como documento na História da Educação foi possível a partir da viragem teórico-metodológica ocorrida no campo da História nas últimas décadas do século 20. Esta viragem historiográfica, denominada de Nova História Cultural, passou a considerar tudo o que é produzido pelo homem comum, quando problematizado, como documento. Nessa perspectiva a ampliação da noção de documento e as novas abordagens historiográficas possibilitam ao pesquisador da educação, preocupado em examinar o vivido na sala de aula, voltar-se aos cadernos escolares, considerados importantes objetos ou fontes de pesquisa (Mignot, 2008), para a compreensão da vida da escola, uma vez que se põem, em análise, métodos e procedimentos experimentados na aula e fora dela.

Como produto da escola estes objetos didáticos têm sido perspectivados a partir da abordagem da História Cultural. A inserção de aspectos culturais, na investigação histórica, possibilitou à História da Educação movimentar novas categorias de análise como a cultura escolar. Em a Escrita da história, Michel de Certeau (2000) propõe uma reflexão acerca da relação entre a prática da pesquisa de campo e a produção do discurso historiográfico. De acordo com o autor a organização de uma narrativa inteligível, que é a prática privilegiada da interpretação histórica, pressupõe a movimentação de uma operação que possibilita ao historiador lançar mão de conceitos que podem ser considerados categorias históricas, na medida em que, ao mesmo tempo, se constroem como unidades de significado, conferindo ordem à documentação, e se desconstroem pelo próprio movimento do arquivo (Certeau, 2000).

A cultura escolar, como categoria de análise histórica cumpre, na História da Educação, o que propõe Certeau (2000): dar novos sentidos e ressignificar os velhos. Ou seja, a cultura escolar possibilita olhar a instituição escolar a partir de perspectivas até então desconsideradas pela História. São novas investigações que oportunizam a produção de novos discursos historiográficos.

Desde 1993, quando Dominique Julia proferiu a conferência de encerramento do $15^{\circ}$ Ische ${ }^{2}$, cujo tema abordou a cultura escolar como objeto histórico, esta categoria de análise histórica subsidia as pesquisas e tem sido insistentemente citada nas investigações do campo da História da Educação ${ }^{3}$.

\footnotetext{
${ }^{2}$ A International Standing Conference for the History of Education - Ische - reúne pesquisadores, investigadores da educação dos diferentes países. Em 1993 a edição do Ische foi sediada em Lisboa e contou com a conferência de encerramento proferida pelo historiador francês Dominique Julia, que abordou a cultura escolar como objeto histórico. O texto desta conferência foi traduzido para o português em 2001 e publicado na primeira edição da Revista Brasileira de História da Educação. Desde então tem sido, usualmente, citado na área da História da Educação.

${ }^{3}$ É relevante destacar que o conceito ou a categoria de análise denominada de cultura escolar não está restrita à História da Educação. Esta categoria é também movimentada em outros campos disciplinares como a antropologia, a sociologia, a filosofia.
} 
Entre as conceituações de cultura escolar mais recorrentes e presentes nas pesquisas em História da Educação no Brasil encontram-se as propostas por Antonio Viñao Frago $(1998)^{4}$, Dominique Julia $(2001)^{5}$ e André Chervel (1990) ${ }^{6}$. Cada um desses autores adota o conceito sob a ótica orientadora das perspectivas de explicação nas práticas internas ou externas à escola, isto é, as concepções de cultura escolar apresentadas por estes autores, mesmo contendo semelhanças e diferenças entre si, consideram a instituição escolar como constituinte de uma cultura própria e localizada historicamente, do mesmo modo que a compreendem como produtora dos documentos dessa cultura. Entre estes documentos, os cadernos escolares, ao serem

tomados em sua materialidade, permitem não apenas a percepção dos conteúdos ensinados, a partir de uma análise dos enunciados e das respostas, mas o entendimento do conjunto de fazeres ativados no interior da escola. Assume destaque, por exemplo, a maneira como o espaço gráfico da página de exercício, do caderno ou da prova é organizado; utilizando-se de formulas indicativas de início ou encerramento de atividades ou dia letivo, definindo uma hierarquia de saberes. [...] Esses objetos culturais e muitos outros, individuais e coletivos, necessários ao funcionamento da aula trazem as marcas da modelação das práticas escolares, quando observados na sua regularidade. Mas portam índices das subversões cotidianas a esse arsenal modelar, quando percebidos em sua diferença, possibilitando localizar vestígios de como os usuários lidam inventivamente com a profusão material da escola e das mudanças, às vezes imperceptíveis, que impetram nessas mesmas práticas escolares. (Vidal, 2004, p. 11)

Nas proposições destes autores os cadernos escolares são um produto da cultura escolar, um dispositivo para a organização do trabalho em sala de aula, um espaço

\footnotetext{
${ }^{4}$ Para Antonio Viñao Frago (1998) a definição de cultura escolar parte do entendimento de que esta é um conjunto de aspectos institucionalizados que caracterizam a escola como uma organização e pode ser considerada em diferentes níveis: podendo ser específica de uma instituição, ou, ainda pode referir-se a um "conjunto o tipos de centros por contraste com otros - por ejemplo, las escuelas rurales o las faculdades de derecho" E, ainda pode referir-se a "un área territorial determinada" ou ao "mundo académico em general por comparación com otros sectores sociales" (p. 68). Esta cultura também diz respeito aos aspectos individualizados de determinados grupos escolares, como alunos, professores, ou de aspectos dos setores organizativos ou institucionais, como, por exemplo, a organização da inspeção escolar. Desta forma os aspectos relacionados ao conjunto institucionalizado irão inserir características e modos de ser e viver que são particulares da escola e envolvem questões da dimensão cotidiana como práticas e condutas, modos de vida, hábitos, objetos, modos de pensar, ideias compartilhadas.

${ }^{5}$ Para Dominique Julia (2001) a definição de cultura escolar é entendida "como um conjunto de normas que definem conhecimentos a ensinar e condutas a inculcar e, um conjunto de práticas que permitem a transmissão desses conhecimentos e a incorporação desses comportamentos" (p. 10). Esta proposição opera um deslocamento da ênfase que, até então, vinha sendo dada pela história das instituições educativas, história das ideias pedagógicas, ênfase na qual o olhar perscrutava apenas o exterior da escola. A proposta de Julia (2001) traz a perspectiva de um olhar para o interior da escola, para o seu funcionamento interno. Para "abrir a caixa preta da escola" (p. 13), o autor propõe três eixos que se colocam como possibilidades para o entendimento da cultura escolar como objeto histórico, a saber: as normas e as finalidades que regem a escola, a profissionalização dos professores e os conteúdos ensinados e as práticas escolares.

${ }^{6}$ André Chervel (1990) concebe as disciplinas escolares como produtos específicos da escola. Nesse sentido define a especificidade de uma cultura produzida pela escola e defende que essa mesma especificidade opera um distanciamento dos esquemas de explicação do saber escolar como um saber inferior ou derivado de saberes superiores, como, por exemplo, os saberes formados pelas universidades. A escola, segundo Chervel (1990), não é um espaço de simples transmissão de saberes, ela é capaz de produzir o seu próprio saber, um saber escolar.
} 
gráfico para o registro dos ritmos, regras e pautas escolares. Os cadernos são fontes privilegiadas de pesquisa, uma vez que configuram espaços destinados ao registro diário das atividades desenvolvidas pelos alunos. Os cadernos são, também, locais de interação entre professores e alunos (Gvirtz; Larrondo, 2008). A ação sobre o caderno escolar demanda uma variedade de modalidades escritas, como: exames, cópias, composições, redações, cartas, ditados.

O uso deste suporte da escrita escolar configura-o como uma das fontes mais idôneas para o estudo do ensino e aprendizagem e dos usos escolares da língua escrita e, ao mesmo tempo, da cultura escrita (Viñao Frago, 2008). Além disso, eles são fontes significativas à pesquisa em História da Educação, uma vez que possibilitam mobilizar indícios acerca da transmissão das diferentes discursos e dos valores no meio escolar, bem como das informações sobre as reformas e sobre as inovações educativas, considerando defasagens e distâncias existentes entre o prescrito pelas propostas teóricas e as apropriações e ressignificações docentes e discentes.

Como produto da cultura escolar, o caderno reflete as demandas produzidas pelo nível, etapa ou ciclo de ensino em que foi utilizado. Nessa perspectiva, este objeto tornase um instrumento que aproxima o pesquisador dos tempos, ritmos, sequências, momentos, hábitos da atividade escolar e possibilita, ao mesmo, compreender até que ponto o real se distancia do oficial ou o segue quanto à distribuição e uso anual, mensal, semanal e diário do tempo escolar (Viñao Frago, 2008).

A materialidade do caderno como produto da cultura escolar potencializa a pesquisa em História da Educação e a História da Cultura Escrita, uma vez que este suporte atua como dispositivo das práticas escolares transformando os saberes, valores ou ideologias em "outra coisa" (Gvirtz; Larrondo, 2008, p. 39). Do mesmo modo, o caderno possibilita ser tratado como fonte histórica se considerado, uma vez que dificilmente na escola este objeto pode ser entendido como neutro, pois traz consigo indícios das mudanças dos conteúdos escolares, do currículo e até mesmo das condições materiais de sua produção.

Nas escolas normais o uso de cadernos escolares ganhou dimensões para além da função de objeto destinado, somente, ao suporte das escritas escolares. A relação dos sujeitos praticantes da cultura escolar - professores, alunos - com este objeto, se problematizada, representa um caminho para a reflexão, do qual, sem dúvida, podem resultar contribuições significativas à escrita da História.

\section{As escolas normais catarinenses e a composição do currículo}

A emergência das escolas normais constituiu uma das experiências educativas mais significativas na História da Educação brasileira. A primeira escola para formação de professores no Brasil foi a Escola Normal de Niterói, fundada em 1835, na capital da província do Rio de Janeiro. Estas instituições permaneceram como únicas responsáveis pela formação de professores primários até o final dos anos de 1950.

A primeira escola normal em Santa Catarina foi criada, na capital do Estado, em 1880, e permaneceu como única instituição pública para a formação de professores até o início da década de 1930, quando se implantou, em Lages, interior do Estado, a segunda escola. Segundo Schaffrath (1999), até 1892 a Escola Normal da capital não manteve um 
funcionamento regular. Foi início da República, com a criação da Escola Normal Catharinense, que ações mais efetivas foram realizadas no âmbito da formação de professores.

O Programa de Ensino da Escola Normal Catharinense, em 1892, determinava que a disciplina de Português fosse lecionada nos três anos do curso. Para a produção escrita o programa instituía que, nos $1^{\circ}$ e nos $3^{\circ}$ anos, o desenvolvimento da redação poderia ser livre, ou seja, o professor definiria o tema e o tipo textual a ser trabalhado. Para o $2^{\circ}$ ano a proposta do programa incidia sob o desenvolvimento de uma descrição orientada. Esta orientação às práticas de escrita manteve-se até os anos 70 do século 20.

A estrutura curricular implantada em 1892 permaneceu inalterada até 1911, quando uma nova reforma no ensino público, autorizada pelo governo de Vidal Ramos (19101914) foi iniciada no Estado ${ }^{7}$. Para conduzir a reestruturação do ensino público, o governo catarinense contratou o professor Orestes Guimarães, formado na Escola Normal da Praça da República de São Paulo. Na função de inspetor geral de ensino, este educador propôs a reforma seguindo as linhas básicas da instrução pública do Estado de São Paulo $^{8}$, em que a seleção das disciplinas, conteúdos e práticas escolares estava ancorada nos valores e nos símbolos republicanos da ciência, da moral, dos valores cívico-patrióticos, do progresso e da ordem. A organização curricular deveria conformar um moderno professor com a competência para instruir e educar as classes populares. Instruir, no sentido de desenvolver e prover de conhecimento a mente da criança, e educar, no sentido de desenvolver-lhe o caráter, a disciplina e as qualidades morais, isto é, dirigir os seus sentimentos e regular a moral (Teive, 2008).

Os aspectos básicos desta reforma permaneceram até o ano de 1935, quando "alterações na filosofia e política de Santa Catarina engendraram uma nova reforma, que teria como principal articulador o inspetor escolar Luiz Sanchez Bezerra da Trindade" (Bombassaro; Silva, 2011, p. 406). A Reforma Trindade transformou as escolas normais em institutos de educação e reafirmou o propósito da formação de técnicos para o magistério catarinense.

A Escola Normal em Lages emergiu no cenário da educação catarinense em um momento no qual as reformas educacionais implantadas eram marcadas pela necessidade da nacionalização do ensino e pela "necessidade de munir o professor de instrumentos mais científicos e racionais para exercer a sua prática” (Daros; Daniel, 2008, p. 253).

Criada pelo decreto n. 445, de 22 de dezembro de 1933, assinado pelo interventor federal no Estado, Aristiliano Ramos, a Escola Normal em Lages tinha como missão ampliar o número de professores primários nas zonas rurais. Em mensagem a Assembléia Legislativa do estado, o interventor justificou a implantação desta escola

\footnotetext{
${ }^{7}$ Lei n. 846, de 11 de outubro de 1910. Estado de Santa Catarina: Seleção de Leis, 1910, p. 6 e 7. Biblioteca Pública do Estado de Santa Catarina.

${ }^{8}$ Sobre a atuação de Orestes Guimarães em Santa Catarina ver TEIVE, Gladys Mary Ghizoni. O professor paulista Orestes Guimarães e a modernização da instrução pública catarinense (1911-1918). Cadernos de História da Educação, n. 6, 2007, p. 107-120; COSTA, Antonio David da. Alguns elementos da história da educação matemática no Estado de Santa Catarina, Brasil, no século 20: a aritmética nos grupos escolares. Hist. Educ. (Online), Porto Alegre, v. 18, n. 44, 2014, p. 27-43. 
como uma "necessidade de formar professores normalistas para exercerem o magistério nas zonas rurais, que por circunstâncias diversas, não é possível frequentar a Escola Normal Catarinense, localizada na capital do Estado" (Ramos, 1934).

Em 21 de fevereiro de 1934, o jornal local $A$ Época divulgava que as inscrições para o exame de admissão para o ingresso na Escola Normal estariam abertas no período entre 27 de fevereiro a 5 de março. Candidata a uma vaga para a Escola Normal, Isolina Gamborgi realizou, em 6 de março de 1934, o exame de admissão ${ }^{9}$ no qual obteve nota 6,80 (A Época, 18/3/1934).

O currículo para $01^{\circ}$ ano da Escola Normal Secundária era composto pelas disciplinas: Português e Literatura, Francês, Alemão, Latim, Aritmética, Álgebra, Geometria, Física, Química, Geografia, Desenho, Música, Trabalhos Manuais, Botânica, História da Civilização, Ginástica, História Natural. Este currículo atendia às orientações prescritas pelo Programa das Escolas Normais de $1928^{10}$. No entanto, a reforma implantada em 1935, que alterou a nomenclatura das escolas normais para institutos de educação, mudou, também, o currículo. O currículo para o $2^{\circ}$ ano do Curso Normal ficou organizado da seguinte forma: Português, Francês, Alemão, Latim, Aritmética, Álgebra, Geometria, Física, Química, Geografia, Desenho, Música, Trabalhos, História da Civilização, História Natural, Educação Física. Para o $3^{\circ}$ ano, o currículo era composto pelas disciplinas de Português e Literatura, Latim, Cosmografia, Física, Química, Geografia, Desenho, Música, Trabalhos, História da Civilização, História Natural, História do Brasil e do Estado, Filosofia, Matemática, Educação Física. As disciplinas que estruturavam o currículo da Escola Normal encontravam-se dispostas no decreto-lei $\mathrm{n}$. 713, de 8 de janeiro de 1935, sendo obrigatórias à formação do normalista.

O currículo prescrito é lei e define os saberes básicos para a formação do sujeito. $\mathrm{Na}$ Escola Normal Secundária em Lages, de acordo com Pinto (2001), em função das dificuldades de contratação de professores e das condições da estrutura física, algumas disciplinas não foram ministradas. No primeiro ano de funcionamento as disciplinas ausentes da formação dos normalistas foram Geometria, História da Civilização, História Natural, Física e Química. No segundo ano a disciplina não ofertada foi a de Educação Física, cujos saberes adentravam o currículo naquele ano. Em 1936, quando da conclusão do Curso Normal, a disciplina não ministrada foi a de Filosofia. Diante deste quadro, uma frente de problematizações se abre a questão da formação proporcionada aos normalistas da primeira turma desta escola.

Entrever o cenário da organização curricular das disciplinas que estruturaram a formação da primeira turma de normalistas em Lages é fundamental para compreender os diferentes usos do caderno de textos produzidos por Isolina Gamborgi, quando essa cursava o segundo ano da Escola Secundária. O Programa da Escola Normal Catarinense prescrevia os "exercícios de redação sobre assuntos fáceis com subsídios fornecidos pelo professor” (Teive, 2008, p. 163). A Reforma Orestes Guimarães, em 1911, instituiu que a disciplina de Português, inclusa nos três anos do curso, "objetivava

\footnotetext{
${ }^{9} \mathrm{O}$ ingresso na Escola Normal ocorria por meio de exames de admissão. Os mesmos eram organizados a partir dos conteúdos das disciplinas de Português, Aritmética, Geografia do Estado e do Brasil e Educação Moral e Cívica. Estas mesmas disciplinas compunham o currículo das escolas complementares.

10 O decreto n. 2.218, de 24 de outubro de 1928, instituiu a organização do currículo para as escolas normais em Santa Catarina. 
assegurar aos futuros professores o patriótico aprendizado do vernáculo, considerado lócus da nacionalidade e meio privilegiado para o fortalecimento da coesão nacional" (Teive, 2008, p. 163). Nessa proposição, o ensino do Português possibilitava à disciplina promover ao estudante situações de aprendizagem em que uma das estratégias era constituir um ensino "eminentemente prático, aplicado de modo a contribuir para proporcionar ao aluno a posse do uso vivo da língua pátria e não de regras abstratas" (Teive, 2008, p. 164). Contrária a essa orientação, o ensino poderia incorrer em falhas e acarretar no aluno o enjoo pelo estudo e o desamor pelas letras (Teive, 2008).

Buscando se distanciar de um ensino que causasse no aluno a repugnância ao trabalho mental (Teive, 2008), a disciplina de Português objetivava o desenvolvimento das práticas de escrita. Para tal, os professores definiram os temas e os tipos de texto a serem desenvolvidos. As produções escritas seriam

corrigidas e comentadas prosódica, ortográfica, sintática e estilisticamente pelo professor; de gramática aos casos ocorrentes, dando-se tudo de acordo com o adiantamento da classe, só por esse meio (...), poderão ser levados aos alunos à posse do mais necessário no uso vivo da Língua Pátria (Programa de Português e Princípios da Literatura da Língua, 1928. (Teive, 2008, p. 164)

Nesta proposição, compreende-se que a produção de textos configurava uma estratégia para o fortalecimento da coesão nacional. Assim, orientar o aluno para a redação de um bom texto era tarefa desempenhada pelo professor na escola normal.

\section{Redações, cartas e composições livres: marcas das práticas de escrita}

Os cadernos escolares começam a circular nas escolas brasileiras nos últimos anos do século 19 e nas primeiras décadas do século 20. De acordo com Souza (1998), foi a partir da escola republicana, que previa uma organização mais complexa e racional, que o caderno adentrou o fazer escolar. O uso do caderno, segundo a autora, estava associado ao barateamento do papel e aos avanços tecnológicos de sua produção. Em vista disso, ele alcançou status de principal suporte da escrita escolar e ganhou força como parte do projeto republicano de educação escolar, um projeto que preconizava a racionalização do ensino e a visibilidade de um ideário de modernização.

Nas escolas de formação de professores o caderno escolar constituiu um importante dispositivo escritural. Sobre a função do caderno, Chartier (2002) sinaliza que este instrumento de escrita ganhou espaço como objeto escolar associado à disciplina, higiene e controle do trabalho desenvolvido pelo aluno. A escrita, neste suporte, impôs ao aluno ordenamentos temporais, espaciais, corporais e intelectuais que são próprios da escola.

O caderno analisado, neste trabalho, faz parte de um conjunto de quatro cadernos utilizados por Isolina Gamborgi entre os anos de 1934 a 1936, período em que a normalista frequentou a Escola Normal Secundária.

Sobre o guardo e a seleção de cadernos, Viñao Frago (2008) sinaliza ser esta uma ação mediada por um processo de subjetividades em que, salvo exceções, são guardados os melhores cadernos, os de capa ou conteúdos esteticamente bonitos, os 
produzidos para exposição. Este autor chama a atenção para não incorrer em tomar estes objetos da cultura material da escola como uma mostra representativa do conjunto de afazeres do aluno em sala de aula.

O caderno de Isolina Gamborgi é uma das exceções destacadas por Viñao Frago (2008). O caderno de textos é uma brochura com folhas costuradas, capa azul escura mesclada com cinza, contém 60 folhas pautadas das quais 58 estão ocupadas com produções textuais escritas a lápis e a caneta. Há no caderno alguns espaços em branco, o que talvez denote a ausência da aluna na aula e a intenção dessa em retomar, repor a atividade perdida, os tipos de letras se diferenciam, sobretudo, nas cartas.

No que diz respeito aos usos e tipos de cadernos que compõem o conjunto, eles estão relacionados às tipologias e aos usos propostos, também por Viñao Frago (2008), em que três destes cadernos enquadram-se no uso de cadernos de trabalho ou caderno de resumo, no qual o aluno sintetiza, estrutura e desenvolve os ensinamentos de uma matéria ou disciplina em função das explicações do professor e de informações procedentes, na maneira de textos escritos. O quarto caderno, objeto de análise deste trabalho, corresponde a um caderno de textos em que as produções mais recorrentes são as elaborações de cartas reais e imaginárias, em que o aluno imagina uma situação e assina como sendo outra pessoa, redações sobre temas sugeridos pelo professor e as composições livres. Estes três tipos de manifestações textuais permitiram uma aproximação com as práticas de escrita em circulação na escola normal, bem como a visualização de técnicas de aprendizagem de escrita e diferentes formas de expressões escritas como cópias, interpretações, entre outras ${ }^{11}$.

O primeiro tipo de texto - a carta - foi, segundo María del Mar del Pozo Andrés e Sara Ramos Zamora (2008), o exercício mais desenvolvido nas escolas. Em um estudo sobre os usos dos cadernos escolares nas escolas espanholas, no período entre 1922 a 1942 , as autoras sinalizam ter sido este tipo de escrita uma das práticas mais exercitadas nas escolas daquele país. Estes exercícios objetivam ensinar aos alunos os rudimentos da forma mais popular e a comunicação entre as pessoas.

No conjunto de cartas redigidas no caderno da ex-normalista pôde-se perceber diferenças na letra, sobretudo nas cartas imaginárias, as quais a aluna assinava com os seguintes pseudônimos: João, Antônio R. e Amir. Neste mesmo conjunto encontraram-se apenas dois exercícios de escrita de carta assinados pela normalista e dizem respeito a uma atividade em que a aluna deveria desenvolver uma carta de pedido, ou seja, pedindo algo a alguém. A primeira versão da atividade deveria ser desenvolvida na $3^{a}$ pessoa do singular e depois transposta para a $3^{a}$ pessoa do plural.

Isolina Gamborgi optou em desenvolver uma redação abordando uma suposta amiga que estava em viagem ao Rio de Janeiro. Nessa conversa solicitava à "Querida Collega" que Ihe trouxesse um livro intitulado Grammatica Francesa, que muito necessitava para o exame de Francês e que não conseguia encontrar em nenhuma das livrarias locais. A disciplina de Francês era ministrada no primeiro e segundo ano da

\footnotetext{
${ }^{11}$ Neste caderno foram encontradas outras formas de escrita como: requerimentos de matrícula, elaboração de ofícios, descrições, procurações, interpretações.

\begin{tabular}{|l|l|l}
\hline Hist. Educ. (Online) & Porto Alegre & v. 20
\end{tabular}

\begin{tabular}{l|l} 
v. 20 & n. 49
\end{tabular}

Maio/ago., 2016

p. $209-226$
} 
Escola Normal. Ao finalizar a carta, a normalista deseja a colega uma "feliz e proveitosa estada que se divirta muito, que areje o espírito cansado de tantos estudos e vigílias, que readquira novas forças para reatar os estudos com maior energia".

No segundo movimento desse exercício a aluna deveria transpor a carta escrita à colega para a $3^{\circ}$ pessoa do plural. $O$ realizado pela aluna apresenta erros de flexão de número. Logo no início da carta já é possível identificá-los. Isolina redige "Querida Collega" (sic) em vez de Queridas Colegas. Há ainda outros erros ao longo do texto, que podem ser observados em destaque na imagem. Todavia, a nota atribuída à atividade é $\underline{9}$ e a existência de erros não foi identificada ou sinalizada pelo professor.

Figura 1-

Página do caderno da ex-normalista que mostra um exercício de escrita de carta.
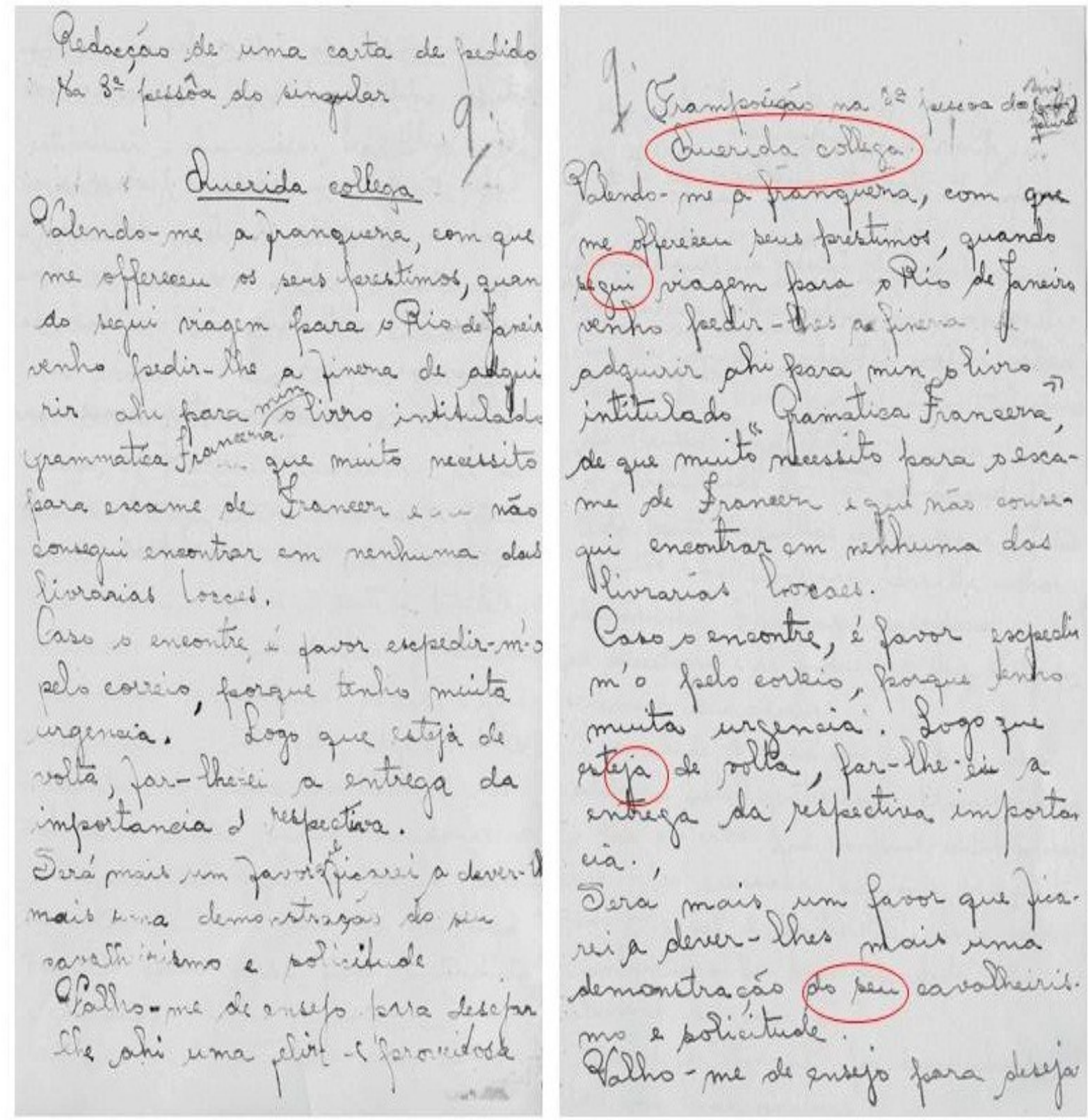

Fonte: Acervo da autora, 2015. 
Outro modelo de carta, presente no caderno da normalista, inscreve-se na categoria de carta imaginária. No caderno analisado este tipo de produção aparece seis vezes. As cartas imaginárias configuravam um tipo de escrita em que o autor colocava-se no lugar de outra pessoa e discorria sobre um determinado tema proposto pelo professor. Isolina Gamborgi escreveu seis destas cartas relatando sobre os temas: descrição de um passeio, descrição de um desastre, descrição de um incêndio, uma carta de despedida, assinando-as como o pseudônimo de João, Antonio R. e Amir. Ao realizar este exercício a aluna modificava o seu traço gráfico, talvez com o intento de dar um realismo à ação.

Outra forma de escrita, presente no caderno da ex-aluna, é a composição livre. Nesse tipo de escrita o aluno desenvolvia o texto em uma extensão mais ampla que a carta e mobilizava argumentações mais livremente que nos ofícios e requerimentos. Todavia, o tema o qual a aluno discorreria era dado pelo professor.

No caderno de Isolina Gamborgi encontram-se sete composições sobre os seguintes temas: um espetáculo teatral, uma fita cinematográfica, uma floresta, sobre o cinema falado, a visita a uma mina de ouro, o combate naval de Riachuelo e sobre uma árvore que cantava. Nestes textos é possível entrever frestas de criatividade e fruição como, por exemplo, na composição sobre o cinema falado em que, alguns excertos da redação, a normalista coloca-se em situações vividas pelo acontecimento, como mostra o destaque na imagem. A narrativa perpassa duas páginas e meia do caderno, o que, se comparado com outras produções escritas como as cartas, por exemplo, é significativa.

Figura 2 -

Página do caderno que mostra o exercício de escrita de uma composição livre.

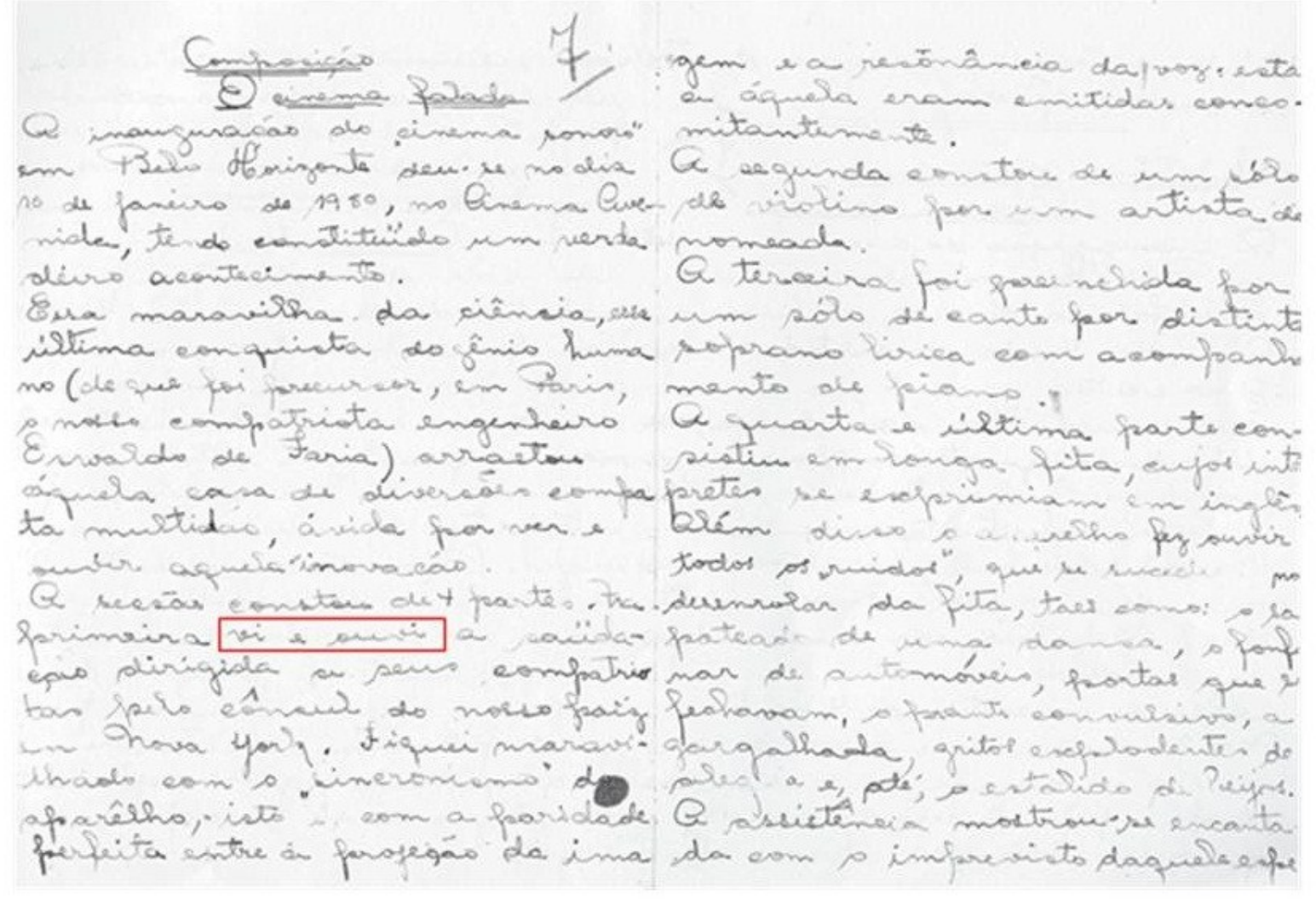

Fonte: Acervo da autora, 2015. 
Há, ainda, outras propostas de escrita baseadas em procedimentos de cópia, memorização e reproduções de modelos como ofícios e requerimentos, que podem dar ênfase a apropriação de recursos gramaticais e retóricos legitimados pelas prescrições curriculares da época.

O programa de Português e os Princípios da Literatura e da Língua orientavam que as produções textuais fossem corrigidas pelo professor. Os textos encontrados no caderno não atendem à normativa. As redações, cartas e composições desenvolvidas pela ex-normalista não apresentam marcas de correção organizadas de acordo com o instituído pelo programa. As marcas de correção emitidas pelo professor ficam restritas a sinais gráficos mantidos, com certa regularidade, por todo o caderno, salvo três exceções, em que o professor assinalou o erro de ortografia presente no texto.

Segundo Lopes (2008), a correção de cadernos escolares apresenta-se como uma tarefa relevante e rotineira no cotidiano de professores e alunos. Essa atividade apoia-se na importância de acompanhar o desenvolvimento do aluno e de, a partir da correção, promover possibilidades para que adquira determinados conhecimentos e prossiga na aprendizagem. O professor da Escola Normal, em nenhum momento no caderno analisado, indicou, orientou, marcou ou promoveu um avanço na escrita da normalista. No entanto, a respeito do não averbar no caderno escolar, retoma-se o alerta de Vinão Frago (2008), quando sinaliza que a produção registrada não corresponde necessariamente ao tempo dedicado àquela tarefa. Por isso mesmo, é importante ter presente que os cadernos escolares também silenciam. Por exemplo, não trazem registros das intervenções orais, gestuais do professor e do aluno.

Assim, afirmar que a normalista não aprendeu, não desenvolveu as competências de escrita, ou ainda, que não teve, por parte do professor, orientações em relação à melhoria na redação de textos, é algo que se constitui um limite a essa investigação, pela impossibilidade de cruzar o caderno analisado com outras fontes. Todavia, o encontrado no caderno da ex-normalista permite questionar sobre a tensão entre o prescrito e realizado. A ausência de correções, conforme orientava o programa de ensino, possibilita problematizar a atuação do professor como a de um transgressor de normas ou, ainda, como a de um consumidor não passivo que fabricou uma nova forma de consumo (Certeau,1994).

Registra-se que neste caderno as marcas de correção estão destacadas dos demais sinais gráficos por meio de forma, cor vermelha, e pela disposição no espaço gráfico da folha do caderno. Se os registros escritos dos alunos devem ser posicionados nos espaços internos das margens e estar alinhado sobre as pautas deste, a mesma situação não ocorre com as marcas de correção do professor que são registradas, afastadas da atividade do aluno, posicionadas à direita ou à esquerda, em destaque na folha do caderno e, ainda, não respeitam a linha da folha, são em geral grafadas na diagonal e evidenciadas por traço abaixo do conceito como o intento de distinguir a ação (Lopes, 2008). Esses aspectos podem ser visualizados nas imagens que ilustram este trabalho.

Em todo o caderno, apresentam-se 23 intervenções do professor com características semelhantes: grafadas em lápis vermelho, localizadas na diagonal da folha, destacadas por um traço abaixo da marcação, em tamanho maior que a grafia do aluno e sem algum comentário, orientação sobre a atividade. Estas marcas indicam a presença do professor no processo de produção dos textos, mas não possibilitam compreender qual a 
participação concreta do professor no processo uma vez que não há inscrições, conceitos, orientações. Somente a representação gráfica numérica ou de "V" - visto - que representa simbolicamente que o professor esteve ali e viu a atividade no caderno. Este ato, simbolicamente se assemelha ao panóptico proposto por Foucault (2003), em que o professor assume o papel de vigilante sobre a atividade do aluno, vê tudo e a marca e, por meio dessa representação, assinala o posicionamento hierárquico das relações institucionais.

Em relação à cor utilizada para grafar a correção, Lopes (2008) sugere que o uso da cor vermelha se deve à distinção entre o registro do aluno e do professor. A grafia em vermelho contribui, também, para direcionar o olhar, num primeiro momento, mais para a marcação do que para a produção de texto do aluno.

A ausência de indicações, ou seja, de marcas de correções nos textos escritos por Isolina Gamborgi, produz sentidos acerca do trabalho docente. Estes sentidos vão do burlar as normas e as regras ao desenvolvimento de táticas para atender outras demandas educativas. A ausência das correções permite ao pesquisador problematizar a relação, a constituição do trabalho e da formação de professores na Escola Normal.

\section{Considerações finais}

As marcas de escrita, representadas pelas redações, cartas e composições livres, presentes no caderno de Isolina Gamborgi, possibilitaram compreender que as orientações de ensino e aprendizagem descritas nos documentos legais que regimentavam as instituições de ensino sofreram apropriações distintas dos consumidores. A ausência das produções textuais corrigidas "prosódica, ortográfica, sintática e estilisticamente pelo professor" (Teive, 2008, p. 164), representa a subversão da tática sobre a estratégia. Nessa concepção, a proposição de Certeau (1994) diz respeito às formas com que os sujeitos individualizam a cultura, alterando coisas e maneiras de fazer que, vão dos usos de objetos utilitários até o cumprimento de leis. Segundo o autor, os indivíduos criam as suas próprias artes de fazer.

Como documento para a pesquisa da História da Cultura Escrita e da História da Educação, o caderno escolar configura um recurso para compreender as relações que se estabelecem entre o currículo prescrito, a prática pedagógica e os usos que se faz deste material didático. Os cadernos como documento oportunizam problematizar a instituição escolar e o seu cotidiano, uma vez que configuram importantes dispositivos para conhecer os autores bem como sua rede de relações, seu modo de expressar conhecimentos, sentimentos, enfim, suas subjetividades.

Os cadernos escolares são vestígios das construções culturais, são objetos, passíveis de serem entendidos para além da materialidade, uma vez que os praticantes da vida escolar deixam, neste suporte, as marcas escritas nas linhas e nas entrelinhas.

\section{Referências}

ANGULO, Kira Mahamud. Adoctrinamiento emocional y socialización política en el primer franquismo (1939-1959): emociones y sentimientos en los manuales escolares de enseñanza primaria. Madrid: Uned, 2012. Tesis (doctoral). Facultad de Educación. 
BADANELLI RUBIO, Ana Maria; MAHAMUD ÂNGULO, Kira. Cuadernos escolares: um ejemplo de la práctica de la escritura em el franquismo. In: CASTILLO GÓMEZ, Antonio; SIERRA BLAS, Veronica (ed.). Mis primeros passos: alfabetización, escuela y usis cotidianos de la escritura (siglos XIX y XX). España: Trea, 2008, p. 259-280.

BOMBASSARO, Ticiane; GASPAR da SILVA, Vera Lúcia. Modernização do estado e reformas do ensino: manifestações da escola nova em Santa Catarina. In: MIGUEL, Maria Elisabeth Blank; VIDAL, Diana Gonçalves; ARAUJO, José Carlos Souza (org.). Reformas educacionais: as manifestações da escola nova no Brasil (1920-1946). Campinas: Autores Associados; Uberlândia: UFU, 2011, p. 405-425.

CERTEAU, Michel de. A invenção do cotidiano: 1. Artes de fazer. Petrópolis: Vozes, 1994.

CERTEAU, Michel de. A escrita da história. Rio de Janeiro: Forense Universitária, 2000.

CHARTIER, Anne Marie. Um dispositivo sem autor: cadernos e fichários na escola primária. Revista Brasileira de História da Educação, n. 3, 2002, p. 9-26.

CHERVEL, Andre. História das disciplinas escolares: reflexões sobre um campo de pesquisa. Teoria \& Educação, Porto Alegre, n. 2, 1990, p. 177-229.

CUNHA, Maria Teresa Santos. No tom e no tema: escritas ordinárias na perspectiva da cultura escolar (segunda metade do século 20). In: BENCOSTTA, Marcus Levy Albino (org.). Culturas escolares, saberes e práticas educativas: itinerários históricos. São Paulo: Cortez, 2007, p. 79-99.

DAROS, Maria das Dores; DANIEL, Leziany Silveira. O curso normal em Santa Catarina: o processo de construção de um projeto de formação de professores coadunados com os ideiais de nacionalização e cientificização do ensino. In: ARAUJO, José Carlos Souza; FREITAS, Anamaria Gonçalves Bueno de; LOPES, Antônio de Pádua Carvalho (orgs.). Escolas normais no Brasil: do império à república. Campinas: Alínea, 2008, p. 249-262.

DEL POZO ANDRÉS, María del Mar; RAMOS ZAMORA, Sara. Representaciones de la escuela y de la cultura escolar em los cuadernos infantiles (España, 1922-1942). In: CASTILLO GÓMEZ, Antonio; SIERRA BLAS, Veronica. (ed.). Mis primeros passos: alfabetización, escuela y usis cotidianos de la escritura (siglos XIX y XX). España: Trea, 2008, p. 259-280.

FOUCAULT, Michel. A verdade e as formas jurídicas. Rio de janeiro: Nau, 2003.

GVIRTZ, Silvina. Del curriculum prescripto al curriculum enseñado: una mirada a los cuadernos de classe. Buenos Aires: Aique, 1997.

GVIRTZ, Silvina; LARRONDO, Marina. Os cadernos de classe como fonte primária de pesquisa: alcances e limites teóricos e metodológicos para sua abordagem. In: MIGNOT, Ana Chrystina Venâncio. Cadernos à vista: escola, memória e cultura escrita. Rio de Janeiro: Uerj, 2008, p. 35-48.

JORNAL A ÉPOCA. 21 de fevereiro de 1934.

JORNAL A ÉPOCA. 18 de março de 1934.

JULIA, Dominique. A cultura escolar como objeto histórico. Revista Brasileira de História da Educação. Campinas, n. 1, 2001, p. 9-43.

KIRCHNER, Cássia Aparecida Sales Magalhães. O caderno de alunos e professores como produto da cultura escolar. CONGRESSO DE ENSINO E PESQUISA DE HISTÓRIA DA EDUCAÇÃO EM MINAS GERAIS, 5, 2009. Anais... Montes Claros: Unimontes, 2009. 
Disponível em <http://www.congressods.com.br/vcopehe/images/trabalhos/6.praticas _escolares_e_processos_educativos/2.Cassia $\% 20$ Aparecida $\% 20$ Sales $\% 20$ Magalhaes $\% 2$ OKirchner.pdf.> Acesso em 12 ago. 2015.

LOPES, Isa Cristina da Rocha. Cadernos escolares: memória e discurso em marcas de correção. In: MIGNOT, Ana Chrystina Venâncio. Cadernos à vista: escola, memória e cultura escrita. Rio de Janeiro: Uerj, 2008, p. 15-34

MIGNOT, Ana Chrystina Venâncio, CUNHA, Maria Teresa Santos. Razões para guardar: a escrita ordinária em arquivo de profesores/as. Revista Educação em Questão. Natal, v. 25 , n. 11,2006 , p. 40-61.

MIGNOT, Ana Crystina Venâncio. Cadernos à vista: escola, memória e cultura escrita. Rio de Janeiro: Uerj, 2008.

MONARCHA, Carlos. Escola normal da praça: o lado noturno das luzes. Campinas: Unicamp, 1999.

PINTO, Flávia Maria Machado. Escola pública em Lages na década de 1930: espaço de disputa política? Florianópolis: UFSC, 2001. 188f. Dissertação (mestrado em Educação). Centro de Ciências da Educação, Universidade Federal de Santa Catarina.

RAMOS, Aristiliano. Mensagem do interventor estadual apresentada ao Congresso Representativo do Estado em 4 de fevereiro de 1934.

SANTA CATARINA. Programma de Ensino da Escola Normal Catharinense. Florianópolis: Gabinete da Typographia Guttenberg, 1908.

SANTA CATARINA. Lei n. 846, de 11 de outubro de 1910.

SANTA CATARINA. Decreto n. 2.218, de 24 dezembro de 1928.

SANTA CATARINA. Decerto lei n. 713, de 8 de janeiro de 1935

SCHAFFRATH, Marlete dos Anjos Silva. A Escola Normal Catharinense de 1892: profissão e ornamento. Florianópolis: UFSC, 1999. 146f. Dissertação (mestrado em Educação). Centro de Ciências da Educação, Universidade Federal de Santa Catarina.

SOUZA, Rosa Fátima de. Templos de civilização: a implantação da escola primária graduadas no Estado de São Paulo (1890-1910). São Paulo: Unesp, 1998.

VIDAL, Diana Gonçalves. Cultura e práticas escolares: uma reflexão sobre documentos e arquivos escolares. s.I.: s.ed., 2004 (Publicado em CD-ROM).

VIÑAO FRAGO, Antonio. Do espaço escolar e da escola como lugar: propostas e questões. In: VIÑAO FRAGO, Antonio; ESCOLANO, Benito. Currículo, espaço e subjetividade. Rio de Janeiro: D\&PA, 1998.

VIÑAO FRAGO, Antonio. Os cadernos escolares como fonte histórica: aspectos metodológicos e histotiograficos. In: MIGNOT, Ana Crystina Venâncio. Cadernos à vista: escola, memória e cultura escrita. Rio de Janeiro: Uerj, 2008, p. 15-34.

TEIVE, Gladys Mary Ghizoni. O professor paulista Orestes Guimarães e a modernização da instrução pública catarinense (1911-1918). Cadernos de História da Educação, Uberlândia, n. 6, 2007, p. 107-120.

TEIVE, Gladys Mary Ghizoni. Uma vez normalista, sempre normalista: cultura escolar e produção de um habitus pedagógico. Florianópolis: Insular, 2008. 
TANIA CORDOVA é estudante no curso de doutorado do Programa de PósGraduação em Educação da Universidade do Estado de Santa Catarina. Mestre em Educação pela Universidade Federal do Paraná.

Endereço: Rodovia Admar Gonzaga, 1935 - Bloco Ell - 88034000 - Florianópolis SC - Brasil.

E-mail: taniacordova@bol.com.br.

Recebido em 20 de setembro de 2015.

Aceito em 16 de janeiro de 2016. 